\title{
EFFECT OF IMPLANT ABUTMENT VENTING ON PERI-IMPLANT SOFT TISSUE RESPONSE . A RANDOMIZED CLINICAL TRIAL
}

\author{
Ahmad Aboelfadl * and Moustafa M Taha**
}

\begin{abstract}
Objective: The purpose of this study was to evaluate the effect of venting of implant abutment on the peri implant soft tissue response in cement retained restorations.

Patients and methods: 14 titanium threaded implants were placed in 14 patients in the premolar maxillary area. 14 crowns were cemented over the abutments where 7 of the abutments were closed design while the other 7 were vented abutments.

A three stage protocol was executed; surgical stage where the implants were placed followed by the prosthetic stage which included placement of abutments of two designs, CAD/CAM provisional crowns were then fabricated and cemented. In the follow- up stage; periodontal and soft tissue esthetic assessments were done at the time of provisional restoration placement (base line), then at 3 months and 6months intervals.
\end{abstract}

Results: Analysis of the results revealed that the effect of the abutment venting (vented and closed) on the peri-implant tissues was statistically insignificant between groups at baseline while significant at follow up intervals.

Conclusion: Vented abutments showed better perimplant soft tissue results at follow up intervals. which seems to be strongly correlated to the less amount of excessive cement extruded in this group.

Clinical significance: Vented abutments should be considered as an alternative to closed ones to decrease the amount of extruded cement for better perimplant outcomes.

KEY WORDS: vented abutment, closed abutment, peri implant soft tissue.

\section{INTRODUCTION}

Fixed implant-supported prosthesis has become the standard treatment for partially or totally edentulous patients. ${ }^{[1]}$ Implant restorations may be screw or cement-retained. Cemented implant restorations have become increasingly common because of their relative fabrication simplicity, decreased laboratory complications, elimination

* Lecturer, Fixed Prosthodontics Department, Faculty of Dentistry , Ain Shams university, Cairo, Egypt, Guest researcher, Oral technology Department, Bonn, Germany.

** Lecturer Oral\&Maxillofacial Surgery Department AinShams University 
of prosthesis screw loosening, improved esthetics and easier control of occlusion compared to screwretained ones. . ${ }^{[2]}$ However, during the process of cementing the restoration onto an implant abutment, cement extrusion can occur with the possibility of leaving excess cement in the surrounding peri-implant tissues associated with soft tissue inflammatory diseases. ${ }^{[3]}$

A direct relation between peri-implant disease and residual cement has been established in the literature, where excess cement is associated with signs of peri-implant disease in almost $80 \%$ of cases. ${ }^{[4]}$ Peri-implant disease is an inflammatory reaction affecting soft and hard tissues surrounding an implant ${ }^{[5]}$ Residual cement extrusion into the periimplant tissues has been associated with this disease resulting in a variety of complications including soft tissue inflammation, foreign body giant cell reaction, soreness, suppuration, bleeding on probing, and loss of the implant supporting bone. ${ }^{[5-7]}$

Implant abutments are available as stock or custom made where both obtain screw access channel, through which the implant-abutment connecting screw can be screwed or unscrewed easily. The screw access channel in the abutment was commonly completely occluded prior to cementing the crown. ${ }^{[8]}$ Crown and abutment designs have a significant role in how the luting cement works and flows. Ideally the abutment-crown configuration should allow for an optimum layer of luting cement; both providing adequate crown retention yet limiting excessive flow. Innovative modifications in abutment designs have been reported, which can control and specifically direct cement flow as abutment venting and internal inserts. ${ }^{[6,9-12]}$

A new innovative technique was introduced in a report by Wadhwani and colleagues to increase volume of retained cement within the crown in order to decrease the amount of extruded cement where they compared the amount of extruded cement around implant/restoration interface when using three abutment types and it was reported that the type with an open screw access and added two vents showed the least amount of extruded cement. ${ }^{[7]}$

These innovations have the potential to direct future abutment design in an effort to improve flow of dental cements and potentially reduce the risk of residual cement extrusion, thus the basis of this clinical study was evaluating the effect of using vented abutments on the peri-implant soft tissues.

\section{PATIENTS AND METHODS:}

\section{Study design and blinding}

This is a randomized, double-blinded clinical trial with an equal allocation rate. Both the patient $\mathrm{s}$ and the evaluator who assessed the soft tissue changes were blinded to the group assignment. The study was held in the clinics of F aculty of Dentistry, Ain Shams University, Cairo, Egypt. All patients were randomly assigned to the study.

\section{Patient's Grouping:}

The present study was conducted on a series of 14 single piece titanium threaded implants which were placed submerged in 14 patients in upper premolar area with immediate crown placement and cement applied on all axial walls of the internal surface of the crown. The patients were divided into two groups according to the abutment design:

- Group (CA): 7 crowns cemented on closed abutments.

- Group (VA): 7 crowns cemented on vented abutments. (Table 1)

TABLE (1) Study grouping

\begin{tabular}{|c|c|}
\hline Closed abutment group (CA) & 7 \\
\hline Vented abutment group (VA) & 7 \\
\hline Total & 14 \\
\hline
\end{tabular}




\section{Eligibility criteria:}

The patients were selected from the outpatient clinic of Crown and Bridge department, Faculty of Dentistry, Ain Shams University, with no sex predilection, systemically healthy patients from 20 to 40 years old with missing upper premolar bounded by a natural tooth anteriorly and posteriorly.

The implants were placed in healed bony site with a ridge width of at least $5.5 \mathrm{~mm}$ and enough bone height to accommodate a $13 \mathrm{~mm}$ implant. Medically compromised patients, heavy smokers, pregnancy, poor oral hygiene, insufficient bone or patients with parafunctional habits were excluded from the study.

\section{Randomization and allocation concealment:}

All participants were randomly divided into two groups according to the abutment design. A person that was not involved in the research protocol performed the randomization procedure by using computer-generated tables. Simple randomization with an equal allocation ratio (www. sealedenvelope. com) was used.

\section{Study materials and protocol}

The materials used in this study were presented in Table 2:

TABLE (2) Materials used in the study

\begin{tabular}{|l|l|}
\hline \multicolumn{1}{|c|}{ Material } & \multicolumn{1}{c|}{ Manufacturer } \\
\hline $\begin{array}{l}\text { Neo CMI implant IS-II } \\
\text { active fixture }\end{array}$ & $\begin{array}{l}\text { Neo Biotech implant system, } \\
\text { Korea. }\end{array}$ \\
\hline Straight closed abutments & $\begin{array}{l}\text { Neo Biotech implant system, } \\
\text { Korea. }\end{array}$ \\
\hline $\begin{array}{l}\text { Polyvinylsiloxane } \\
\text { impression material (Putty) }\end{array}$ & Panasil - Kettenbach, USA \\
\hline $\begin{array}{l}\text { Polyvinylsiloxane } \\
\text { impression material (Light) }\end{array}$ & Panasil - Kettenbach, USA \\
\hline Dentotemp Temporary cement & Itena clinical products, France \\
\hline Vipiblock (PMMA) blanks & Vipi ,Brazil \\
\hline
\end{tabular}

\section{Pre- surgical procedures}

Diagnostic cast evaluation: Alginate impressions had been taken and poured to obtain diagnostic casts for to be mounted on mean value articulator to detect the presence of an adequate inter-arch distance and to assess alignment of teeth, horizontal and vertical jaw relationships.

Clinical photographs: Clinical photographs were taken including the implant site and at least one adjacent tooth on each side to ensure comparability.

Radiographic examination: Standardized CBCT scanning procedures were done for all patients by the same radiologist operating a $\mathrm{CT}$ machine (PLANMECA ProMax)*

Implant planning: The proper implant diameter and length were selected guided by the CBCT measurements keeping a $2 \mathrm{~mm}$ safety margin of intact bone between the implant and the floor of the maxillary sinus and $1.5 \mathrm{~mm}$ between the implant and the adjacent teeth as shown in Figure 1

Surgical guide designing and fabrication: The surgical guide was fully digitally designed and fabricated where the completed surgical template was exported as an STL file ready for printing in 3D printer.

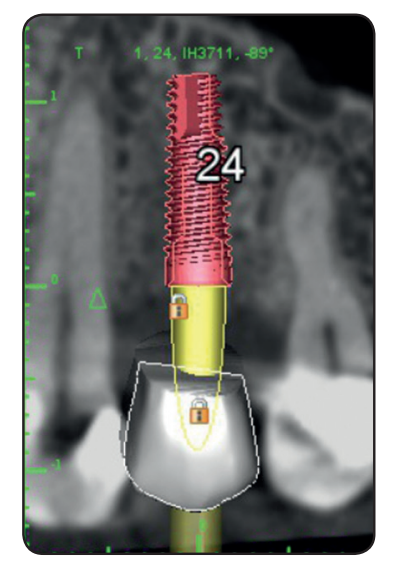

Fig. (1) Implant Planning

\footnotetext{
* Planmeca Oy, Helsinki, Finland
} 
The study design included three stages:

\section{Stage 1: Surgical Stage:}

1-Pre-surgical medication: Strict oral hygiene measures were advised to each patient one week before surgery.

2- Surgical Procedures: Neobiotech surgical tray kit* and Dentis simple guide surgical kit** were used for implant placement. During drilling no lateral movement was done. Only vertical motion is allowed to avoid detachment of the metal sleeves and/or fracture of the guiding tubes. Healing caps were inserted for 48 hours healing.

\section{3-Postoperative care and medications:}

Patients have been instructed to follow a postsurgical medication, oral hygiene measures and instructions

\section{Stage 2: Prosthetic Stage:}

1-Impression making: Implant impression copings were screwed over the implants for final impression which was made using vinyl polysiloxane impression material with open tray

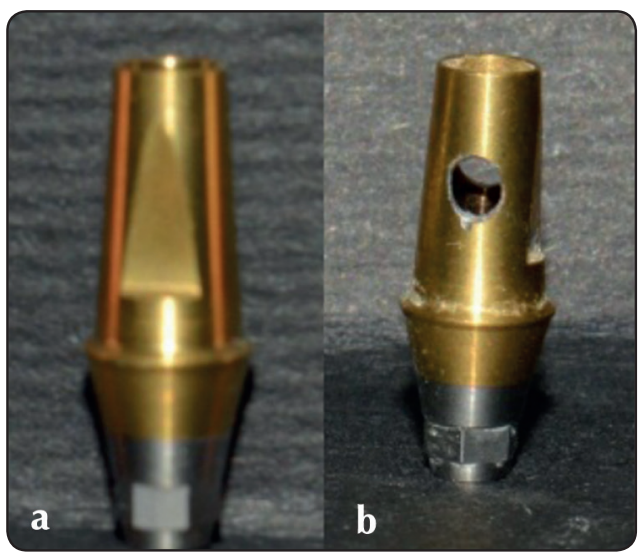

Fig. (2) a) closed abutment b) vented abutment one-step impression technique followed by pouring of stone models.

2-Abutment preparation: The abutments were prepared to receive the PMMA crowns.

Seven abutments were kept closed while the other seven were modified by placing vent holes internally where 2 holes, $180^{\circ}$ apart approximately $3 \mathrm{~mm}$ below the occlusal surface were done using round bur size 2 with head diameter $1 \mathrm{~mm}$. Figure 2

\section{3- PMMA crowns fabrication:}

Scanning of the poured models was done using Identica blue hybrid desktop scanner ${ }^{* * * *}$. Designing of the crowns was done using Exocad software $^{* * * * *}$ with $80 \mu \mathrm{m}$ cement gap starting $1 \mathrm{~mm}$ above the margin and nonfunctional occlusion with the opposing teeth. The temporary crowns were milled using CAD/CAM Vhf S1 five axis milling machine $^{* * * * * *}$ out of PMMA blanks to match the contours and contact areas of their contra lateral counter parts allowing the soft tissues to adapt to optimal contours. The healing caps were removed from the patient's mouth and the final abutments (closed or vented) were removed from the cast and

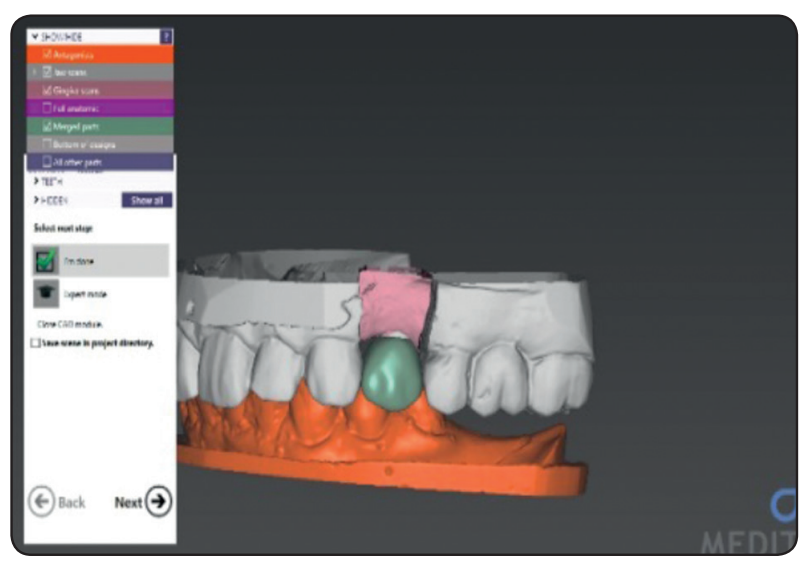

Fig. (3) CADCAM Crown fabrication

\footnotetext{
* Neobiotech Inc., Los Angeles, USA.

** Dr. Amr EL Khadem, Cairo, Egypt.

*** MEDIT corp. Seoul, Korea

**** Exocad GmbH, Darmstadt, Germany

****** Vhf, Ammerbuch, Germany

$* * * * * *$ Itena , France.

***** Hu-Friedy, Chicago, USA.
} 
tightened over the implants, then the restorations were placed over the corresponding abutments and checked for contact, occlusion and shade. Figure 3

4- Cementation: Long term temporary cement (Dentotemp)*** was used to cement the PMMA crowns over the abutments. The amount of cement used is measured on a calibrated mixing pad. $3 \mathrm{~mm}$ of cement is used each time to coat the internal surface of the crowns using a size 2 brush.

The abutment screw access was closed before the crown is cemented on the closed abutment group while a Teflon tape was used to cover the screw head keeping the screw access hole opened in the vented abutment group.

Finger pressure was used for seating the crown and held in position for 1 minute then the patient was instructed to bite on cotton roll for 5 minutes. The restoration margin was carefully checked and excess cement was removed using a round blade sickle scaler***** and dental floss was used for checking of cement removal. Conventional brushing and flossing were permitted. Figure 4

Stage 3: Post-restoration follow-up implant evaluation stage:

All follow up assessments were made by two well-trained blinded observers different from the implant surgeon and prosthodontist and the mean of their scores was recorded. Base line clinical examination and photographs were performed at the time of crown cementation, and re-examination was scheduled 3 and 6 months intervals for evaluating the following parameters:

\section{1st: Periodontal assessments:}

The following periodontal parameters were assessed at the mesial, buccal, distal and lingual aspects of each implant (test) and the adjacent natural teeth (control):

i. Gingival marginal level :The location of the peri-implant mucosal or gingival margin in relation to the inferior border of the crown over the implant or the cemento-enamel junction of the natural adjacent teeth was determined to the nearest $\mathrm{mm}$.

ii. Pocket probing depth (PPD): The periodontal probe with $1 \mathrm{~mm}$ markings and $0.45 \mathrm{~mm}$ probing tip diameter was inserted into the sulcus with little force and the pocket depth was measured to the nearest millimeter from the gingival or peri-implant mucosal margin to the bottom of the sulcus.

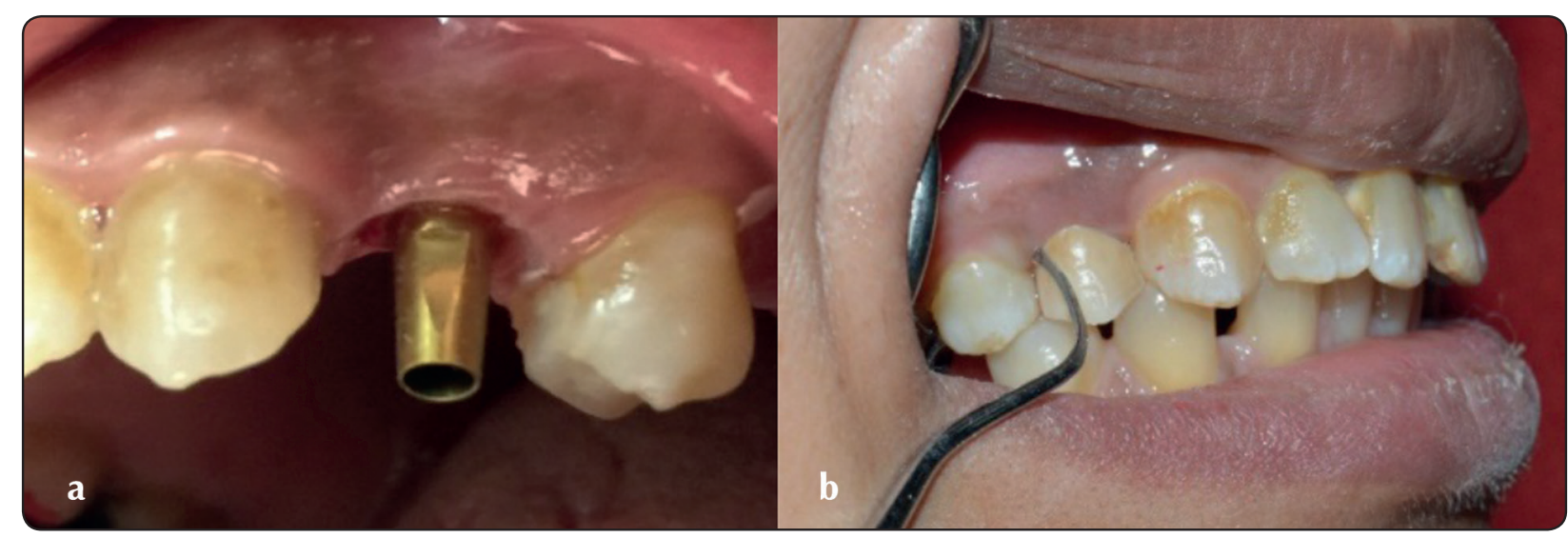

Fig. (4) a . Abutment inserted b. Crown cemented

* Hu-Friedy, Chicago, USA. 


\section{iii. Modified plaque index (Oral hygiene status) (PII):}

Presence or absence of visible plaque at the soft tissue margin was assessed and scores were given.

0: no detection of plaque

1: plaque only recognized by running a probe across the smooth marginal surface of the implant

2: plaque can be seen by naked eye

3: abundance of soft matter

\section{$2^{\text {nd }}$ : Soft tissue esthetic assessments, PES:}

The Modified pink esthetic score (PES)comprises the following five variables: mesial papilla, distal papilla, curvature of the facial mucosa, level of the facial mucosa, and root convexity/soft tissue color and texture at the facial aspect of the implant site. A score of 2,1, or 0 was assigned to all five PES parameters.

The five described parameters ( 5 X 2) add up, under optimum conditions, to a score of 10 ; the threshold of clinical acceptability was set at 6 .

All clinical \& follow up data were then tabulated $\&$ statistically analyzed

\section{Statistical analysis}

Data presented as mean, standard deviation $(\mathrm{SD})$, frequency $(\mathrm{N})$ and percentage $(\%)$ when appropriate. Kruskal Wallis test used to compare between different tested groups for non-parametric data. One Way ANOVA used to compare between tested groups followed by pairwise comparison for with Tukey's posthoc test for parametric data. The significance level was set at $\mathrm{P} \leq 0.05$. Statistical analysis was performed with IBM ${ }^{\circledR}$ SPSS ${ }^{\circledR}$ (SPSS Inc., IBM Corporation, NY, USA) Statistics Version 25 for Windows.

\section{RESULTS}

\section{Gingival marginal level}

Difference between tested groups for Mean Gingival marginal level:

Mean and standard deviation (SD) for Gingival marginal level for different tested groups presented in table (3) and figure (5).Considering the follow up periods there was no statistically significant difference between groups at the base line and in the 6 months follow up while there was a statistically significant difference between closed and vented at 3 months follow up.

TABLE (3) Mean and standard deviation (SD) for Gingival marginal level for different tested groups

\begin{tabular}{|c|c|c|c|c|c|c|}
\hline \multicolumn{2}{|c|}{} & \multicolumn{2}{|c|}{ CA } & \multicolumn{2}{c|}{ VA } & \multirow{2}{*}{ P value } \\
\cline { 2 - 6 } & Mean & SD & Mean & SD & \\
\hline \multirow{2}{*}{$\begin{array}{c}\text { Gingival } \\
\text { marginal } \\
\text { level }\end{array}$} & Immediate & 3.33 & 0.58 & 3.50 & 0.50 & $0.503 \mathrm{NS}$ \\
\cline { 2 - 7 } & 3 Months & 4.33 & 0.58 & 3.17 & 0.58 & $0.003^{*}$ \\
\cline { 2 - 6 } & 6 Months & 4.50 & 0.50 & 4.33 & 0.58 & $0.567 \mathrm{NS}$ \\
\hline
\end{tabular}

*= Significant, NS=Non-significant

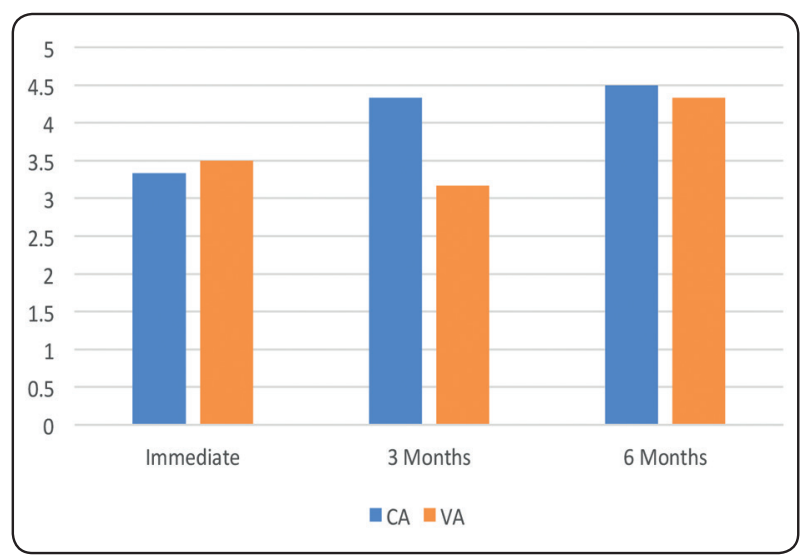

Fig. (5) Bar chart showing the mean Gingival marginal level for different tested groups. 


\section{Probing Depth ( $\mathrm{mm})$}

\section{Difference between tested groups for Mean Prob-} ing Depth (mm):

Mean and standard deviation (SD) for Probing Depth $(\mathrm{mm})$ for different tested groups presented in table (4) and figure (6).

Considering different intervals of the followup period, the difference in probing depth between tested groups was statistically non-significant as indicated by $\mathrm{t}$ test $(\mathrm{p}>0.05)$.

TABLE (4) Mean and standard deviation (SD) for Probing Depth (mm) for different tested groups

\begin{tabular}{|c|c|c|c|c|c|c|}
\hline \multicolumn{2}{|c|}{} & \multicolumn{2}{|c|}{ CA } & \multicolumn{2}{c|}{ VA } & \multirow{2}{*}{ p-value } \\
\cline { 2 - 6 } & Mean & SD & Mean & SD & \\
\hline \multirow{4}{*}{$\begin{array}{c}\text { Probing } \\
\text { Depth } \\
\text { (mm) }\end{array}$} & Immediate & 2.39 & 0.93 & 2.28 & 1.03 & 0.837 NS \\
\cline { 2 - 6 } & 3 Months & 2.78 & 1.30 & 2.11 & 0.89 & $0.283 \mathrm{NS}$ \\
\cline { 2 - 6 } & 6 Months & 2.94 & 1.33 & 1.83 & 0.75 & $0.078 \mathrm{NS}$ \\
\hline
\end{tabular}

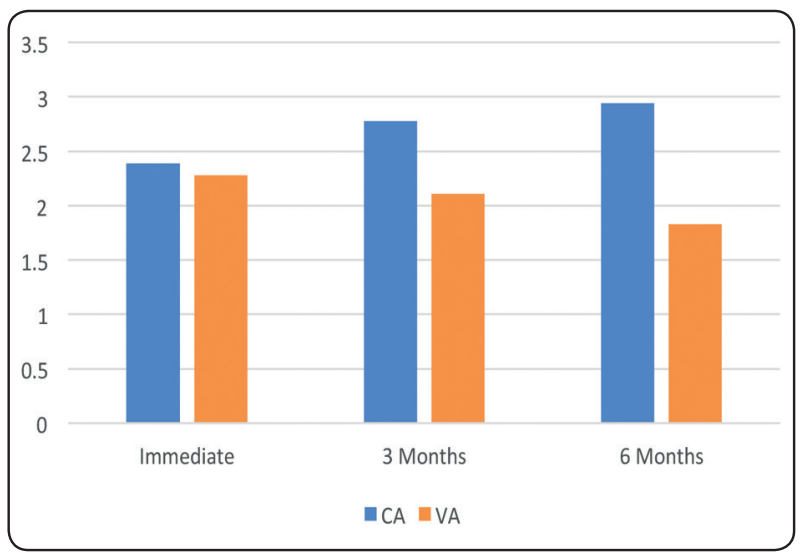

Fig. (6) Bar chart showing the mean Probing Depth (mm) for different tested groups.

\section{Modified pink esthetic score}

\section{Difference between tested groups for Mean Mod- ified pink esthetic score:}

Mean and standard deviation (SD) for Modified pink esthetic score for different tested groups presented in table (5) and figure (7).

Considering the follow up periods there was no statistically significant difference between groups at the base line follow up while there was a statistically significant difference between closed and vented abutments in 3 months follow up and in the 6 months

TABLE (5) Mean and standard deviation (SD) for Modified pink esthetic score for different tested groups.

\begin{tabular}{|c|c|c|c|c|c|c|}
\hline \multicolumn{2}{|c|}{} & \multicolumn{4}{|c|}{ Group Ax } & \multirow{2}{*}{ p-value } \\
\cline { 2 - 6 } & \multicolumn{2}{|c|}{ CA } & \multicolumn{2}{c|}{ VA } & \\
\cline { 2 - 6 } & Mean & SD & Mean & SD & \\
\hline $\begin{array}{c}\text { Modified } \\
\text { pink } \\
\text { esthetic } \\
\text { score }\end{array}$ & Immediate & 8.00 & 0.87 & 8.56 & 0.53 & 0.172 NS \\
\cline { 2 - 6 } & 6 Months & 7.78 & 0.97 & 8.78 & 0.67 & $0.004^{*}$ \\
\hline
\end{tabular}

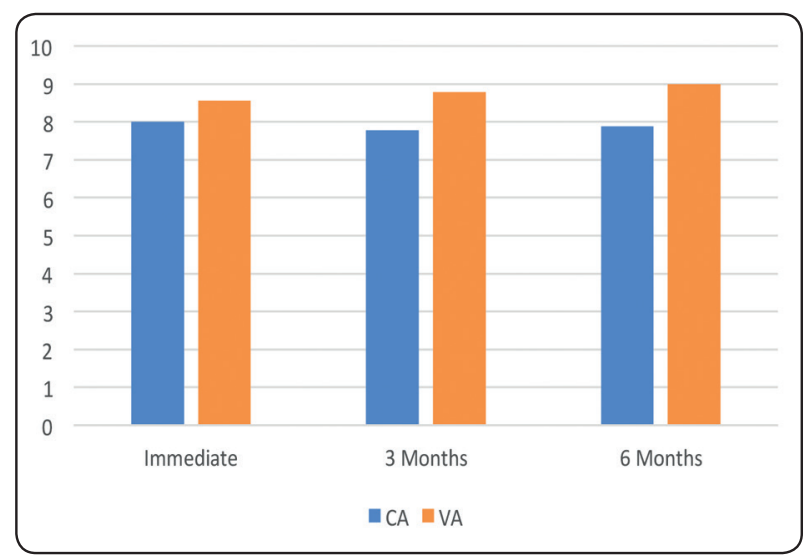

Fig. (7) Bar chart showing the mean Modified pink esthetic score for different tested groups. 


\section{DISCUSSION}

The perimplant soft tissue regarding its biological and esthetic conditions is one key factor for a successful implant restoration. A direct link between peri-implant disease and residual cement has been demonstrated in the literature. ${ }^{[4]}$ Moreover, residual excess cement has been reported as a risk factor by the American Academy of Periodontology consensus report on peri-implant disease. ${ }^{[13]}$ Studies have reported that removal and prevention of all residual cement is of high priority during implant prosthetic procedures ${ }^{[5,7]}$

One fact to be considered during planning for cemente retained implant restorations is to deal with the crown, implant abutment, and cement as an integrated system, with each component contributing to how the system functions and how to control excess cement extrusion to ensure ideal biological and esthetic outcome.

A variety of implant abutments are introduced by the manufacturers in terms of material, angulation, and design .It was considered a common practice to close an abutment screw access before the crown is cemented, however, modifying the abutment by placing vent holes has the added advantage of changing the way the cement flows and the amount of cement kept within the abutment. ${ }^{[7]}$

It has also been suggested by Patel et al that the presence of a vent hole in the implant abutment, regardless of location or diameter, provides a path for the escape of excess cement to not only enable a better seating, but also to reduce the amount of cement actually being expressed at the margin. ${ }^{[6]}$

Although many clinical studies have reported a positive impact of venting the abutment on peri-implant soft tissues, yet the data have still been inconclusive $\&$ up to date the literature still lacks providing clinical evidence about the true influence of these factors on preserving soft tissue. Accordingly, the current study was conducted to evaluate the influence of venting the abutment on variable biological \& esthetic outcomes around single tooth implants.

Single implant restorations were only included in this study to ensure the presence of neighboring teeth as a reference and for interdental papillary support, while restoring multiple missing teeth and areas with bone or soft tissue deficiencies needs special surgical and prosthetic approaches beyond the scope of our study. It should be also mentioned that the maxillary premolar area has been the one of interest in our search as it combines the high concern of both esthetics and function.

Standardization of factors that can influence the results such as: age range, bone quality, implant type, surgical technique and loading periods was achieved throughout the study. Moreover, all patients received the same treatment protocol performed by a team of the same implantologist, prosthodontist and laboratory technician. Additionally, implants of all subjects included in the study were randomly assigned to one of the treatment protocols to avoid any bias among different treatment protocols.

Prosthetic driven approach, Computer-assisted drilling guides and flapless technique have been used to provide ideal implant placement angulation, minimal invasion together with less postoperative complications, minimized crestal bone loss, and to facilitate the establishment of favorable forces on the implant and the prosthetic component ensuring predictable prosthetic outcome. ${ }^{[14,15]}$

Implant planning was done according to the available mesio-distal and bucco-lingual dimensions of the edentulous area which was estimated on the CBCT where a safety zone of bone was left around the implant of $2 \mathrm{~mm}$ between the implant and the floor of the maxillary sinus and about $1.5 \mathrm{~mm}$ between the implant and the adjacent teeth. ${ }^{[16]}$

Prosthetic procedures and loading were preformed immediately within the first 48 hours of implant placement to allow executing our investigations following an immediate loading approach which is recommended nowadays especially in esthetic areas 
with minimal functional risk factors. As for the laboratory steps, they were are all done using CAD/ CAM technology to achieve high levels of accuracy as the temporary crowns were designed and milled of a standard anatomy, size and cement gap $(30 \mu \mathrm{m})$ to ensure maximum standardization possible for cement space available for all the samples.

Temporary crowns have been our choice for immediate loading as they temporization is well known to develop soft tissue contours and support and maintain the interdental papilla during the healing phases.Moreover, the high level of fracture resistance for the CAD/CAM temporary crowns allows their use as long-term temporary solution on implants. ${ }^{[17,18]}$

Long term temporary cementation was also used in our study because retrievability of implant prosthetic components is a significant safety factor. ${ }^{[19]}$ Among a variety of cements DentoTemp (Itena Co. Paris, France) was recommended and used in the study due to its low film thickness $(14 \mu \mathrm{m})$ as claimed by manufacturer, high radiopacity that is beneficial to detect excess cement in radiographs and high mechanical properties compared to other temporary cements. ${ }^{[20]}$

Evaluation of esthetic outcomes in the current study goes with Belser et $\boldsymbol{a l}^{[21]}$ who pointed out to the measurement of esthetic outcomes in clinical studies and suggested that a selective assessment of peri-implant soft tissues with an objective score would help to evaluate implant-supported restorations. PES was used as an objective score for evaluation of peri-implant soft tissue esthetics. It integrates the height and level as well as the color and texture of peri-implant soft tissue .PES was first used in 2005 by Furhauser et al ${ }^{[22]}$ for soft tissue evaluation around 30 single-tooth implant crowns and their results revealed that PES is a suitable instrument for reproducibly evaluating soft tissues around single-tooth implant crowns and monitoring long term soft tissue alterations.
This outcome was supported by another study in 2008 by Gehrke et al ${ }^{[23]}$ who found that the PES allows for a more objective appraisal of the esthetic short- and long-term results of various surgical and prosthetic implant procedures. It reproducibly evaluates the peri-implant soft tissue around singleimplant restorations and results in good intraexaminer agreement. Beside the esthetic soft tissue assessments, classical periodontal parameters in terms of PPD, BOP, PI and soft tissue condition were measured for clinical monitoring of implant soft tissue health.

When measuring the effect of the abutment design (vented and closed) on the peri-implant tissues it was found that there was statistically significant difference between groups regarding almost all periodontal parameters except for pocket probing depth. This might be due to the vents utilized in the abutment, which control the flow of throughout the abutment during the entire crown seating as revealed by a finite element analysis study on novel vented dental abutment geometries for cement-retained crown restorations who concluded that venting dental abutments can be accomplished to allow for improved dental cement flow within the system. However, they also stated that the abutment geometry must be carefully designed to ensure mechanical stability. ${ }^{[24]}$

The difference observed in Gingival level and being of better values among vented abutments at follow upmight be justified by the better control on residual extruded cement in such abutments with better periodontal parameters values which goes well with Scully et al. 2007 who demonstrated that the adequate removal of excess cement can result in resolution of the peri-implant disease if early addressed. ${ }^{[25]}$ Our results are also in consistent with Thomas $\boldsymbol{G}^{[4]}$ who observed significantly that majority of the tissues surrounding the implants demonstrating signs of peri-implant disease had retained excess cement in the subgingival spaces. 
Analysis of soft tissue esthetics in terms of modified PES revealed also statistically significant difference between groups with vented abutments showing the best esthetic results at 3 and 6 months follow up. Of interest from an esthetic point of view is the topography of the surrounding soft tissues i.e. the position of the soft tissue margin at the facial aspect of the crown, since it will dictate clinical crown length and cervical form of the implant-supported crown and the degree of interdental papillae fill. Again, this better esthetic behavior seems to be strongly correlated to the less excessive cement extruded in this group as previously described by Wadhwani and Chung ${ }^{[26]}$.One explanation is that when a crown that seats fully onto an abutment is cemented; an inverse relationship exists between the amount of retained cement and that extruded at the crown-abutment margin for a given amount of cement. So it would be reasonable that increasing the free space by opening the screw channel would increase the amount of cement to be retained inside the crown and decreased amount of cement would be extruded.

In another study by Wadhwani et al ${ }^{[7]}$ the results showed that venting the hollow abutment resulted in the least amount of cement extrusion when compared to closing off the screw access channel. Within the limitations of the study, it was concluded that the use of two, $1 \mathrm{~mm}$ radius vent holes placed 3 $\mathrm{mm}$ apical to the occlusal area of the abutment and 180 degrees apart will limit the amount of cement extruded into the gingival sulcus of implant-retained crowns.

Furthermore, this outcome was also supported by continuous study by Wadhwani and Chung [27] who found out that modifying the internal configuration of the screw access channel of implant abutment affected the amount of extruded cement. It is also worth mentioning that a study using novel computational fluid dynamics approach achieved virtual model simulation results following those of a physical actual cement-retained crown-implant abutment study emphasizing the fact that abut- ment modifications has a major effects on cement flow that may in turn have clinical periimplant implications. ${ }^{[10]}$

Accordingly, using vented abutments while applying the cement on the internal walls of the crown in the current study resulted in decreasing the amount of excess extruded cement and therefore better soft tissue health was recorded at follow up. The common general finding regarding both groups was that all biological and esthetic outcomes were within the normal health limits, remained relatively stable. This could be related to the atraumatic conservative surgical approach a conclusion which agrees with Patil et al ${ }^{[28]}$ who followed the same conservative surgical and meticulous prosthetic procedures that may preserve the soft and hard tissues from damage.

Limited number of patients, accurate observation of patient inclusion/exclusion criteria, conservative surgical technique, strict periodontal and prosthetic monitoring and short observation period, could be considered important co-factors for a high shortterm successful rate observed in the study groups.

\section{CONCLUSION}

Within the limitations of this study, the following conclusions could be drawn:

Peri-implant esthetic and biological outcomes of both abutment designs were within the normal health limits and remained relatively stable throughout the six months follow up period of the study.

Vented abutments exhibit less excess cement extrusion and better soft tissue response at follow up intervals .

Additional properly designed studies with more relevant number of patients and long-term followup is recommended in order to establish the long term effect the abutment design on peri-implant soft tissue health and esthetics. 


\section{REFERENCES}

1. Pennington J, Parker S. Improving quality of life using removable and fixed implant prostheses. Compend Contin Educ Dent 2012;33:268-74.

2. Squier RS, Agar JR, Duncan JP, Taylor TD. Retentiveness of dental cements used with metallic implant components. Int J Oral Maxillofac Implants 2001; 16:793-798.

3. Gapski R, Neugeboren N, Pomeranz AZ, Reissner MW. Endosseous implant failure influenced by crown cementation: A clinical case report. Int J Oral Maxillofac Implants 2008; 23:943-946.

4. Wilson, Jr., T.G. The positive relationship between excesscement and peri-implant disease: a prospective clinical endoscopicstudy. J. Periodontol. 2009; 80(9), 1388-1392.

5. Wilson, Jr., T.G., Valderrama, P., Rodrigues, D.B. The case for routine maintenance of dental implants. J. Periodontol. 2014;85(5),657-660.

6. Patel, D., Invest, J.C. , Tredwin, C.J. , Setchell, D.J. , Moles, D.R .An analysis of the effect of a vent hole on excess cement expressed at the crown-abutment margin for cement-retained implant crowns.J. Prosthodont. 2009; 18(1), 54-59.

7. Wadhwani, C. , Piñeyro, A. , Hess, T. , Zhang, H. , Chung, K.H. Effect of implant abutment modification on the extrusion of excess cement at the crown-abutment margin for cement retained implant restorations. Int. J. Oral Maxillofac. Implants 2011; 26(6), 1241-1246.

8. Tarica DY, Alvarado VM, Truong ST. Survey of United States dental schools on cementation protocols for implant crown restoration. J Prosthet Dent 2010;103:68-79.

9. Schwedhelm, E.R., Lepe, X., Aw, T.C., 2003. A crown venting technique for the cementation of implant-supported crowns. J. Prosthet. Dent. 89(1), 89-90.

10. Wadhwani, C. , Goodwin, S. , Chung, K.H., 2014. Cementing an implant crown: a novel measurement system using computational fluid dynamics approach. Clin. Implant Dent. Relat. Res. DOI: 10.1111/cid.12258.

11. Wadhwani, C. , Rapoport, D. , La Rosa, S. , Hess, T., Kretschmar, S., 2011. Radiographic detection and characteristic patterns of residual excess cement associated with cement-retained implant restorations: a clinical report.

12. Wadhwani, C., Hess, T., Pineyro, A., Chung, K.H., 2013. Effects of abutment and screw access channel modification on dislodgement of cement-retained implant-supported restorations. Int. J. Prosthodont. 26(1), 54-56.

13. American Academy of Periodontology. Peri-implant mucositis and peri-implantitis: a current understanding of their diagnoses and clinical implications. J Periodontol 2013; 84:436-643.

14. William Becker, Moshe Goldstein, Burton E. Becker. Minimally Invasive Flapless Implant Surgery: A Prospective Multicenter Study. Clinical Implant Dentistry and Related Research. 2005;7:85-98.

15. Daniel V, Matts A, Inger W. A Computed Tomographic Scan-Derived Customized Surgical Template and Fixed Prosthesis for Flapless Surgery and Immediate Loading of Implants. Clinical Implant Dentistry and Related Research 2005;7:13-19.

16. Misch CE: Single tooth implants. In Misch CE (eds). Contemporary Implant Dentistry, pp.397-428.Mosby 1999.

17. Matani J, Jambhekar S, Kheur M, Sethi S, Kheur S .'Customized impression post: An innovative way for esthetic implant restorations' Journal of Implant and Advanced Clinical Dentistry 2013;13-17.

18. Martin Rosentritt, Philipp Raab, Sebastian Hahnel, Matthias Stöckle, Verena Preis. In-vitro performance of CAD/ CAM-fabricated implant supported temporary crowns. Clin Oral Invest 2017, 21:2581-2587.

19. Konstantinos X. Michalakis,Argiris L. Pissiotis, Hiroshi Hirayama. Cement Failure Loads of 4 Provisional Luting Agents Used for the Cementation of Implant-Supported Fixed Partial Dentures. Int J Oral Maxillofac Implants. 2000;15:545-549.

20. Castillo R, Lynch C, Turrion A, Lopez J, Torres D, Suarez MJ. Misfit and microleakage of implant-supported crown copings obtained by laser sintering and casting techniques, luted with glass-ionomer, resin cements and acrylic/urethane-based agents. J Dent.2013; 41:90-96.

21. Belser UC, Schmid B, Higginbottom F, et al.: Outcome analysis of implant restorations located in the anterior maxilla: a review of the recent literature. Int J Oral Maxillofac Implants 2004;19:30-42.

22. Furhauser R, Florescu D, Benesch T. Evaluation of soft tissue around single-tooth implant crowns: the pink esthetic score. Clinical Oral Implants Research. 2005;16: 639-644.

23. Peter Gehrke, Markus L, Gunter D. Reproducibility of PES rating soft tissue esthetic around single implant restorations. J Esthet Restor Dent. 2008;20: 375-385. 
24. Lucas C. Rodriguez, Juliana N. Saba, Clark A. Meyer, Kwok-Hung Chung, Chandur Wadhwani ,Danieli C. Rodrigues. A finite element analysis of novel vented dental abutment geometries for cement retained crown restorations. Clinical and Experimental Dental Research 2 (2), 136-145.

25. Scully, C. ,Hobkirk, J. ,Dios,P.D., 2007.Dental endosseous implants in themedically compromised patient. J. Oral Rehabil. 34(8), 590-599.

26. Wadhwani C, Kwok Chung. The Role of Cements in
Dental Implant Success. Int J Oral Max illofac Im plants. 2013;27:859-864.

27. Wadhwani C, Kwok Chung. Effect of modifying the screw access channels of zirconia implant abutment on the cement flow pattern and retention of zirconia restorations. $\mathrm{J}$ Prosthet Dent 2014;12:45-50.

28. Ratnadeep Patil, Marco M. Gresnigt, Kavita Mahesh, Anjali Dilbaghi. Esthetic Evaluation of Anterior SingleTooth Implants with Different Abutment Designs. Journal of Prosthodontics 2017;26: 395-398. 